\title{
YERBILIMLERI
}

Bulletin for Earth Sciences

Yerbilimleri, 2019, 40 (1), 92-109, DOI:10.17824/yerbilimleri.532270

Hacettepe Üniversitesi Yerbilimleri Uygulama ve Araştırma Merkezi Bülteni

Bulletin of the Earth Sciences Application and Research Centre of Hacettepe University

\section{Betonarme Yapılarda Gerilmenin Neden Olduğu Deformasyonların Jeofizik} Yöntemlerle Araştırılması

Investigation of the Deformations Caused by Stress in a Reinforced Concrete Structure with Geophysical Methods

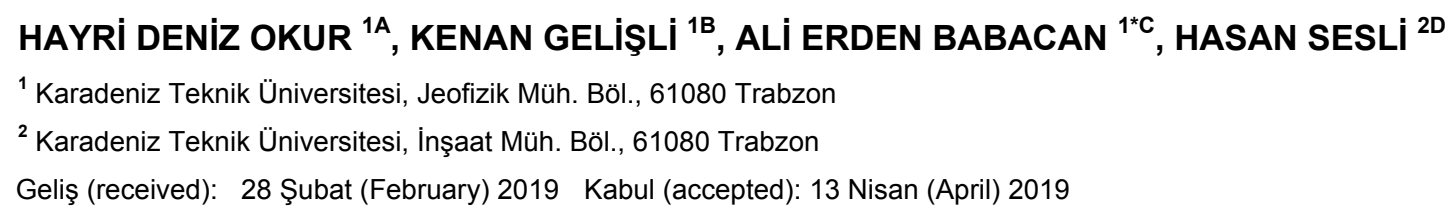

\section{ÖZ}

Deprem kuşağında bulunan ülkelerde, can ve mal güvenliği için betonarme yapıların kalitesi önemlidir. Bu yapıların kalitesini, yapının temel elemanları olan betonun ve betona gömülü çelik donatıların durumu belirler. Betonarme yapıların durumu yapıya herhangi bir zarar vermeden belirlenmelidir. Jeofizik yöntemlerle, betonarme yapıda hiçbir delgi veya karot alma işlemi yapılmaksızın tamamen hasarsız olarak beton dayanımı, betona gömülü çelik donatıların yerlerinin tespiti ve korozyon durumu belirlenebilir. Belirlenen bu özellikler karot örneği gibi sadece yapının küçük bir kısmını değil bütün yapıyı temsil eder. Sismik ultrasonik yöntem ile betonarme yapılar üzerinde yapılan ölçümlerle, betonun kırık-çatlak yapısı, dayanımı, elastik parametreleri ve betonun içindeki boşluklar belirlenerek betonun kalitesi tespit edilebilir. Yer radarı (GPR) yöntemi kullanılarak, betonun içindeki donatıların yerleri, aralıkları, sayıları ve beton içerisindeki boşluklar belirlenebilir. Elektrik özdirenç yöntemi kullanılarak ta betonun nemliliği ve donatıların korozyon durumu ortaya konulabilir. Bu çalışmada, yapılarda deprem dayanımını arttırmak için üretilmiş bir yapı elemanının durumu, çevrimsel yük uygulanmadan önce ve çevrimsel yük uygulandıktan sonra araştırılmıştır. Betonun kalitesi ve nemliliğini, yapının donatılarının yerlerini, donatıların korozyon durumunu ve yüzeyden görülmeyen çatlakları incelemek amacıyla oluşturulan betonarme yapı elemanı üzerinde jeofizik ölçüler alınmıştır. Bu amaçla, sismik ultrasonik, yer radarı ve elektrik özdirenç yöntemleri kullanıımıştır. Çalışmada 18 profildeki 176 noktada sismik ultrasonik, 85 profilde iki ve üç boyutlu yer radarı, 25 profilde de özdirenç ölçümleri alınmış ve

A Karadeniz Teknik Üniversitesi, Jeofizik Müh. Böl., 61080 Trabzon, ORCID 0000-0001-9398-7825, hdo48@hotmail.com

B Karadeniz Teknik Üniversitesi, Jeofizik Müh. Böl., 61080 Trabzon, ORCID 0000-0002-9512-2611, gelisli@ktu.edu.tr

c Karadeniz Teknik Üniversitesi, Jeofizik Müh. Böl., 61080 Trabzon, ORCID 0000-0002-8216-5225, a.babacan@ktu.edu.tr

D Karadeniz Teknik Üniversitesi, İnşaat Müh. Böl., 61080 Trabzon ORCID 0000-0003-3328-5922, :sesli@ktu.edu.tr 
değerlendirilmiştir. Yapılan değerlendirmeler sonucunda, kullanılan yöntemler ile yapının kalitesi, nemliliği, donatıların yerleri ve korozyon durumu belirlenmiştir.

Ayrıca, betonarme yapı elemanına uygulanan kuvvet sonrası, yapıda meydana gelen yapısal değişimler de bu yöntemler ile açıkça gözlenebilmiştir. Bu araştırmada yapıya herhangi bir zarar vermeden, hızı bir şekilde alınan sismik ultrasonik, GPR ve mikro özdirenç ölçülerinin yapının görünmeyen kısımları hakkında önemli bilgiler sağladığı ortaya konulmuştur.

Anahtar Kelimeler: Sismik ultrasonik, yer radarı, elektrik özdirenç, yapı kalitesi.

\section{ABSTRACT}

The quality of reinforced concrete structures is important for the safety of life and property in countries located in a earthquake zone. The quality of these structures is determined by the state of the structural elements embedded in concrete and concrete. The state of the reinforced concrete structures must be determined effectively without damaging the structure. With geophysical methods, concrete strength can be determined completely without any drilling or coring, and the location and corrosion status of steel reinforcements embedded in concrete can be determined. These properties, as the core sample, represent not only a small portion of the structure but the whole structure. With the measurements made on the concrete structure by seismic ultrasonic method, the fracture-crack structure, strength, elastic parameters and cavities in the concrete can be determined and the quality of the concrete can be determined. Ground Penetrating Radar (GPR) method can be used to determine the reinforcement locations, spaces, numbers and cavities within the concrete. The moisture content of the concrete and the corrosion condition of the reinforcement can be determined by using the electrical resistivity method. In this study, the condition of a structural element designed to increase the earthquake resistance in structures was investigated before and after a cyclic loading test. Geophysical measurements were taken to investigate the quality and humidity of the concrete, the location of the reinforcement of the structure, the corrosion condition of the reinforcement and the cracks not visible from the surface. For this purpose, seismic ultrasonic method, ground penetrating radar method and electrical resistivity methods were used. In the study, ultrasonic measurements were performed at 176 locations in 18 profiles, two and three dimensional ground radars in 85 profiles and resistivity 
measurements in 25 profiles. As a result of the evaluations made, it is understood that the methods used have revealed the quality of the structure, humidity, location of the reinforcement and corrosion condition. In addition, the effects of applied loading on these properties were investigated. In this study, it has been shown that the ultrasonic, GPR and micro resistivity measures taken quickly without any damage to the structure provide important information about the invisible parts of the structure.

Keywords: Ultrasonic, GPR, electrical resistivity, structure quality.

\section{GíRiş}

Türkiye, toprakları içerisinde bulunan yıkıcı deprem potansiyeline sahip aktif faylar nedeniyle bir deprem ülkesidir. Ülkemizde geçmişte yıkıcı depremler meydana gelmiş ve gelecekte de meydana gelecektir. Ülkemizde, diğer yapı türlerine göre sağladığı pek çok avantaj nedeniyle barınmak için çoğunlukla betonarme yapılar tercih edilmektedir. İnşaat sektöründe betonarme yapıların depreme dayanıklılığını arttırmak için perde elemanlar gibi özel yapı elemanı tasarımları yapılmaktadır. Son yıllarda kullanılmaya başlanan bu sistemler, yapıyı deprem kuvvetlerine karşı güçlendirmekte, ayrıca kirişler üzerine monte edilen metal amortisörlü kirişler ile depremlerin oluşturduğu yanal yöndeki enerji sönümlenerek depremin binaya vereceği zarar azaltmaktadır. Şekil 1'de sol tarafta klasik betonarme kirişli bir yapı elamanı, sağ tarafta ise metal amortisör ilave edilmiş sönümlü kiriş sistemi görülmektedir. Uygulanan deprem benzeri bir kuvvet etkisi ile klasik kiriş sistemi kullanılamayacak şekilde hasar alırken amortisörlü kiriş sistemi uygulanan enerjiyi sönümleyerek daha az hasar görmüştür (Ahn vd., 2011).

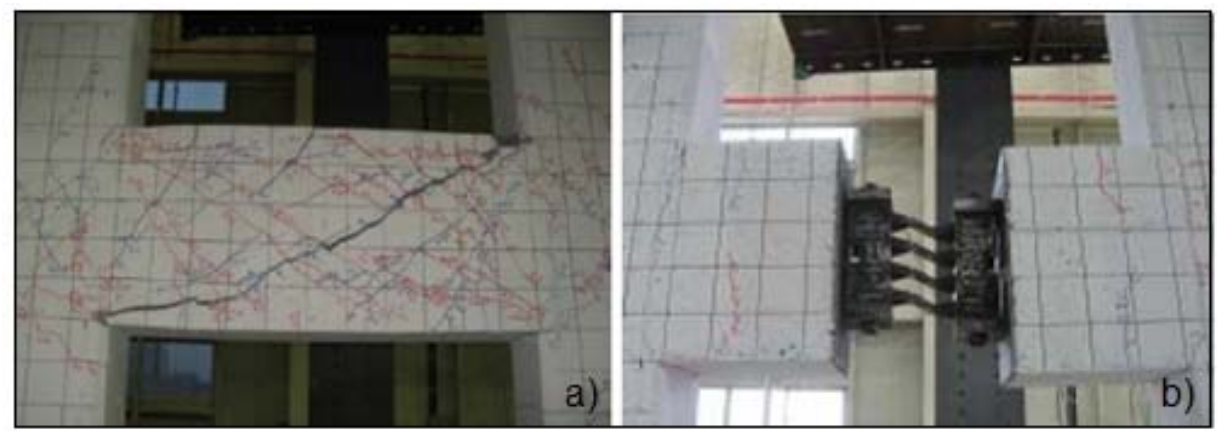

Şekil 1. Test amacı için üretilmiş betonarme bir yapı elemanı a) betonarme kiriş b) metal kiriş bağlantı sistemlerinin görünümü (Ahn ve diğ., 2011).

Figure 1. A reinforced concrete structural element for the purpose of testing a) reinforced concrete beam b) an appearance of metal beam connection systems (Ahn et al., 2011).

Son yıllarda yapı araştırmalarında tahribatsız olarak uygulanan jeofizik yöntemlerin kullanımı giderek artmaktadır (Cecire, 2003; Barroso vd., 2006; Gosa'lbez vd., 2006; Nuzzo vd., 2010; Diana ve Fais, 2010; Akevren, 2010; Uyanık vd., 2011; Babacan ve 
Gelişli, 2015; Solla vd., 2016; Mechbal ve Khamlichi, 2017; Özçelik ve Gelişli, 2018). Nuzzo vd. (2010)'da GPR, kızılötesi termografi (IRT) ve ultrasonik yöntemleri kullanarak Troia Katedrali'ni (Apulia, İtalya) incelemişler ve ultrasonik hız yöntemi sonuçlarına göre kolonlar için yarı nicel bir kalite sınıflaması yapmışlardır. Babacan ve Gelişli (2015) yllında Trabzon ilinde yer alan Ayasofya ve Gülbahar Hatun camilerinin mermer sütunlarını ultrasonik hız ölçüm yöntemi ile incelemişler ve sütunlarının sağlam olan ve bozuşmaya uğrayan kısımlarını ortaya çıkarmışlardır. Özçelik ve Gelişli (2018)'de bir köprü yapısının elemanı olarak üretilen düşey bir betonarme yapı elemanında GPR, ultrasonik ve elektrik özdirenç yöntemlerini uygulayarak, yapının kırık çatlak durumu, beton kalitesi, donatıların yeri ve korozyon durumunu belirlemişlerdir. Sabbağ ve Uyanık (2018) yılında kuru ve suya doygun koşullar altında farklı kuvvetlerde donatılı ve donatısız olarak tasarlanmış beton örnekleri üzerinde elektrik özdirenç değişimlerini incelemişlerdir.

Bu çalışmada, metalik sönümleyici tipi bağ kirişli boşluklu betonarme perde duvar sisteminin durumu ve uygulanan deprem benzeri bir kuvvet etkisi ile meydana gelen değişimler jeofizik yöntemlerle araştırılmıştır.

\section{ARAŞTIRMADA KULLANILAN JEOFIZIK YÖNTEMLER Sismik Ultrasonik Yöntem}

Sismik ultrasonik yöntem yapay kaynaklarla üretilerek malzeme içerisine gönderilen ses (akustik) dalgalarının araştırma yapılan kütle içerisinde yayılarak alıcı aletlerle kaydedilmesi esasına dayanan bir jeofizik yöntemdir (Jones ve Gatfield, 1955). Kaydedilen parametre ses dalgasının kaynaktan çıkıp alıcıya gelmesi için geçen zamandır. Ayrıca, kaynak ve alıcı uzaklığı ölçülebildiğinden, bilinen bir parametre olarak hesaplarda kullanılmaktadır. Betonarme elemanların dayanımları tarihsel olarak daima silindirik veya kübik beton numunelerin laboratuvarda kırılması yolu ile tayin edile gelmiştir. Hâlbuki ultrasonik dalga yayılma hızı tahribat yapmaksızın ölçülerek, betonun basınç dayanımı güvenilir bir hassasiyetle belirlenebilir. Sismik ultrasonik yöntemde çoğunlukla boyuna dalgalar (P-dalgası) kullanılmaktadır. Katı materyaller içinde ultrasonik dalganın seyahat hızı daha çok materyalin elastik özelliklerine ve yoğunluğuna bağlıdır. 
Ultrasonik hız ölçümlerinde kullanılan alet, ultrasonik hız ölçüm cihazı, verici-alıcı başlıklar ve yüksek voltaj darbe (puls) üreteci olmak üzere üç kısımdan meydana gelir (Şekil 2a). Bu cihaz 0.1 ile 0.9999 mikro saniye arasında geçiş zamanını, yine 1 ile 9999 m/sn arasında da darbe (puls) hızını ölçebilecek biçimde düzenlenmiştir. Bu özelliği nedeniyle yumuşak ve zayıf veya sert, masif numunelerde duyarlı ölçümler yapma olanağı sağlamaktadır. Sinyal biriktirme özelliği, zayıf sinyallerden kaliteli bir dalga şeklinin üretilmesini sağlar. Piezoelektrik özelliğe sahip verici başlıkla, cihaz tarafından üretilen ultrasonik dalgalar mekanik titreşime çevrilerek numuneye aktarılır. Frekans aralığı $24 \mathrm{kHz}$ ile $1 \mathrm{MHz}$ arasında değişmektedir. Frekans artıkça dalga boyu küçülmektedir. Genel olarak P-dalgası ölçümlerinde $54 \mathrm{KHz} l i k$ alıcı ve vericiler kullanılmakla birlikte üreteç yardımı ile gözenekli ve çatlaklı numunelerde de ölçümler yapılabilmektedir (Popovics, 2003).
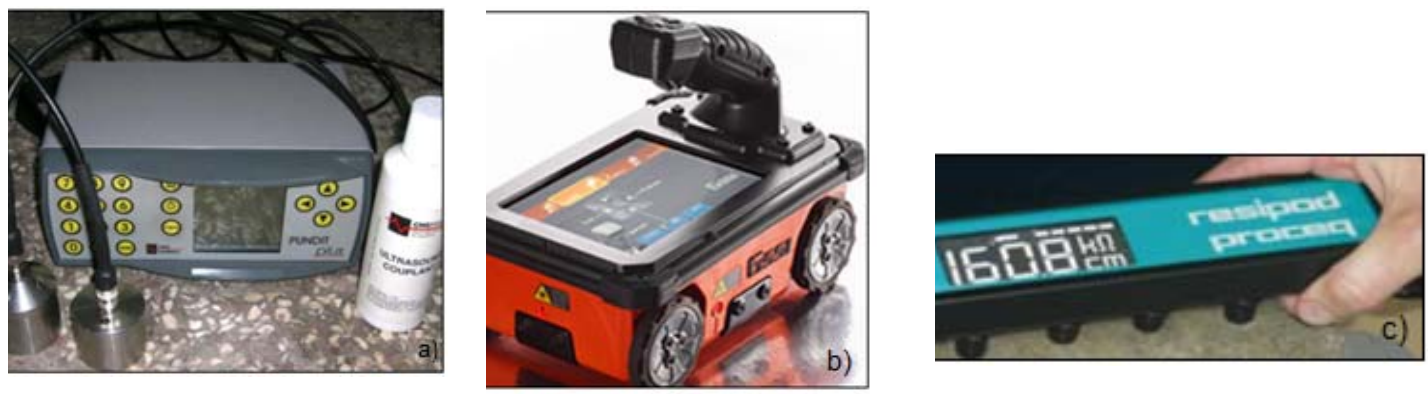

Şekil 2. a) Çalışmada kullanılan ultrasonik hız ölçüm cihazı ve alıcı-verici başlıklar b) yüksek frekanslı yer radarı cihazı c) elektrik özdirenç ölçer

Figure 2. a) Ultrasonic velocity measuring device and transmitter and receiver transducers used in the study b) high frequency ground penetrating radar device c) electrical resistivity meter.

Ultrasonik hız ölçüm teknikleri, alıcı ve vericinin numune üzerindeki konumlarına göre direk, yarı direk ve yüzey iletim (indirekt) tekniği olmak üzere üç farklı şekilde uygulanabilmektedir. Direkt iletim tekniğinde, alıcılar ve vericiler ölçüm yapılacak numunenin paralel yüzeyleri üzerine zıt doğrultularda yerleştirilerek yol geçiş zamanı veya hızlar ölçülebilmektedir. Yarı direkt iletim tekniğinde, verici numunenin yan tarafında yer alırken alıcı ise numunenin üst tarafına yerleştirilerek ölçüm alınır. Yüzey iletim tekniğinde ise, alıcı ve verici numunenin aynı yüzeylerine yerleştirilerek ölçüm alınmaktadır. Boyuna $(P)$ dalganın numuneyi kat ediş süresi cihaz veya kayıt üzerinde okuduktan sonra, numune boyu $(\mathrm{m})$, kat ediş zamanına oranlanarak $V_{\mathrm{P}}$; P- dalga hızı 
(m/sn) hesaplanır. Betona ait sismik hızlar ultrasonik yöntem ile ölçüldükten sonra betonun özelliklerini veren parametreler ilgili bağıntılar kullanılarak hesaplanır. Çizelge 1'de P-dalgası hızlarına göre beton kalitesi değerleri verilmiştir (Leslie ve Cheeseman, 1949; Feldman, 1977). Buna göre beton malzemede kolay ve hızlı bir şekilde ölçülecek ultrasonik hızlar haritalanarak betonun kalite dağılımı ortaya konulabilir. Ultrasonik hızlar ve hızlardan hesaplanan elastik parametrelerle beton dayanımı ilişkileri konusunda pek çok çalışma gerçekleştirilmiştir (Krautkramer, 1969; Green, 1973; Singh ve Sharma, 2008).

\begin{tabular}{|c|c|}
\hline Beton Kalitesi & Vp [m/s] \\
\hline Çok iyi & $>4500$ \\
\hline İyi & $3600-4500$ \\
\hline Orta & $3000-3600$ \\
\hline Zayıf & $2100-2900$ \\
\hline Çok zayıf & $<2100$ \\
\hline
\end{tabular}

Çizelge 1. Ultrasonik hız ile beton kalitesi ilişkisi (Leslie ve Cheeseman, 1949; Feldman, 1977).

Table 1. The relationship between ultrasonic velocity and concrete quality (Leslie and Cheeseman, 1949; Feldman, 1977).

\section{Yer Radarı Yöntemi}

Yer radarı, araştırılan ortamın sığ derinliklerini yüksek çözünürlükte görüntüleyebilen elektromanyetik bir yöntemdir. Yöntem ile malzeme içerisine gönderilen ve zaman içinde değişen yüksek frekanslı elektromanyetik alanlar kullanılarak incelemeler yapılmaktadır. Kayaç içerisine gönderilen bu alan, kayacın yönbağımlı (anizotropik) yapısının etkisi ile değişmekte ve kayaç içindeki yapıların (kırık, çatlak ve boşlukların) elektriksel özelliklerinin değişiminin gözlenmesine izin vermektedir (Davis ve Annan, 1986; Daniels, 2004). Bir verici antenle gönderilen yüksek frekanslı elektromanyetik dalgaların bir kısmı, malzeme içerisindeki farklı dielektrik özelliklere sahip yüzeylerden yansırken, diğer kısmı da malzeme içerisine ilerlemeye devam etmektedir. Alıcı bir anten ise geri gelen sinyalleri algılamaktadır. Alınan sinyaller kontrol biriminde biriktirilmekte ve çift yol seyahat zamanı nanosaniye cinsinden kaydedilmektedir (Davis ve Annan, 1986; 1989). Yöntemin kullanımının kolay olması ve çok hızlı veri toplanabilmesi, veri toplama sırasında çalışma alanında herhangi bir tahribat oluşturmaması (non-invasive), santimetre hatta milimetre 
düzeyinde yüksek çözünürlüklü iki boyutlu ve üç boyutlu görüntülemenin yapılabilmesi yöntemin en önemli avantajlarıdır. Yöntemde genel olarak yer altındaki gömülü yapılar ve bunların özelliklerini haritalamak için $10 \mathrm{MHz}$ ile $6000 \mathrm{MHz}$ frekans aralığında radyo dalgaları kullanmaktadır. Burada sözü geçen toplam seyahat zamanı, radar dalgasının yüzeydeki verici antenden çıkıp yeraltında süreksizlikle/süreksizliklerle karşılaştığı ve bu yüzeyden yansıyarak yeryüzündeki alıcı antende kaydedildiği ana kadar geçen süredir. Nüfuz (etki/ penetrasyon) derinliği ve radar sinyalinin çözünürlülük (ayrımlılık) gücü iletilen dalganın frekansına ve araştırılan ortamdaki malzemenin dielektrik özelliklerine bağlıdır. Kullanılan farklı frekanslar hem nüfuz derinliğini hem de çözünürlülüğü etkiler. Düşük frekanslarda araştırma derinliği artarken, düşey çözünürlülük azalmaktadır. Yüksek frekanslarda ise düşey çözünürlülük artarken, nüfuz derinliği azalmaktadır (Annan, 2001).

Yöntem yüksek çözünürlülükte görüntü vermesi nedeniyle yapı jeofiziğinde yaygın olarak kullanılmaktadır. Yapı jeofiziğinde daha çok kolon, sütun gibi sığ ortamlar araştırıldığından genellikle yüksek frekanslı antenler kullanılır. Yüksek frekanslı yer radarı aleti genellikle elde taşınabilen boyutlarda, alıcı ve verici anteni içinde bulunduran, hızlı uygulanabilen, pratik ve ekonomik aletlerdir (Şekil 2b). Yer radarı cihazı ile ölçülen ham verilerinden araştırılan yapıyı değerlendirmek veya görüntülemek zor olduğundan bu verilerin işlenmesi gerekmektedir (Annan, 2001; Daniels, 2004). Verilerin işlenmesiyle elde edilen iki ve üç boyutlu kesitlerle araştırma yapılan yapı yüksek çözünürlükle görüntülenmiş olur. Betona gömülü borular, kablolar, donatılar, donatıların sayısı ve yeri, beton içerisindeki çatlaklar, boşluklar yapıya hiçbir zarar vermeden belirlenir.

\section{Elektrik Özdirenç Yöntemi}

Elektrik özdirenç yöntemi yerin elektrik iletkenliğindeki değişimi ölçen jeofizik bir yöntemdir. Bu amaç için yeryüzüne iki noktadan elektrik alan uygulanır ve diğer iki nokta arasında gerilim farkı ölçülür. Elektrik alanın uygulandığı elektrotlar "akım elektrotları" ve gerilim farkının ölçüldüğü elektrotlar "gerilim elektrotları" olarak adlandırılır. Elektrotların ölçüm sırasındaki çeşitli konumlarına göre geliştirilen ölçü alım teknikleri, elektrot açılımları olarak adlandırılır. Akım elektrotları arasındaki uzaklığın arttırılması akımın daha derinlere inmesini sağlar ve dolayısıyla daha derinlerin özdirenç özellikleri hakkında bilgi toplanır. Elektrik özdirenç yönteminin esası Ohm Kanunu'na dayanır. Yöntem, 
ortamların sahip olduğu farklı fiziksel değişimlere bağlı olarak elektrik akımını iletme (veya direnç gösterme) özelliğinin ölçülmesine dayanmaktadır. Aynı malzemenin su içeriği değiş̧imi özdirenç değişimlerini etkilemektedir. Yöntem hakkında ayrıntılı teorik bilgi Telford vd. (1990)'da verilmiştir.

Beton nemliliği ve içerisindeki donatının korozyon durumunu belirlemek için tahribatsız jeofizik yöntemlerden elektrik özdirenç yöntemi kullanılır. Yapı jeofiziğinde kullanılan cihazlar genellikle aynı derinlikten bilgi sağlayan Wenner dizilimine göre tasarlanmıştır (Telford vd., 1990) ve özdirençler k $\Omega \mathrm{cm}$ cinsinden ölçülür (Şekil 2c). Kullanılan elektrik özdirenç cihazında elektrot aralığı 5 cm'dir. Ölçülen elektrik gerilim 1-5 mVolt olacak şekilde, akım elektrotlarından 250 mikro Amper seviyelerinde 25-150 Hz frekanslı akım geçirilir. Sabit elektrot aralıklı Wenner dizilimi ile araştırılacak yüzey üzerinde her noktada ölçüm alınarak profil boyunca ilerlenir. Böylece araştırma yaptığımız bütün yüzeyin aynı derinliğinden bilgi alınmış olunur. Farklı profillerden elde edilen veriler haritalanarak yapının o derinliğine ait özdirenç dağılım haritası oluşturulur. Betonarme içindeki demirin korozyonu akım akışı meydana getiren ve metalleri çözebilen elektrokimyasal bir işlemdir. Genel olarak demir korozyonu arttıkça beton özdirenci azalır. Elektrik özdirençkorozyon derecesi ilişkisi Çizelge 2'de görülmektedir.

\begin{tabular}{|c|c|}
\hline Korozyon Derecesi & Beton özdirenci ( $\mathbf{\Omega} . \mathbf{m})$ \\
\hline Az korozyon & $\geq 200$ \\
\hline Orta derecede korozyon & $100-200$ \\
\hline Yüksek derecede korozyon & $50-100$ \\
\hline Çok yüksek korozyon & $\leq 50$ \\
\hline
\end{tabular}

Çizelge 2. Yapıda ölçülen elektrik özdirenç ile korozyon derecesi ilişkisi (Andrade ve Alonso, 2004).

Table 2. The relationship between the degree of corrosion and electrical resistivity measured in the concrete (Andrade and Alonso, 2004).

\section{YAPILAN ÇALIŞMALAR}

Karadeniz Teknik Üniversitesi İnşaat Mühendisliği yapı laboratuvarında depreme dayanıklı yapı geliştirme projesi çerçevesinde bir perde yapı elemanı hazırlanmıştır. Yapı 
elemanında kiriş olarak metal sönümleyici sistem kullanılmıştır. Ölçümlerin alındığı perde duvarın ölçüleri 1350×750x200 mm'dir. Metalik sönümleyicinin bağlı olduğu betonarme bağ kirişi kollarının ölçüleri ise 450×215×200 mm'dir. Betonarme kısımların kalınlığı standart olarak 200 mm'dir. Yapı elemanında kullanılan betonun kalitesi 35 Mpa olarak ölçülmüştür. Pas payları $2 \mathrm{~cm}$ 'dir. Yapı elemanı üzerinde gerilme öncesi ve gerilme sonrası jeofizik ölçülerle yapının durumunun ve durumundaki değişimlerin değerlendirilmesi amaçlanmaktadır. Bu çerçevede, gerilme uygulanmadan önce ve gerilme sonrasında yapı üzerinde beton dayanımı, korozyon durumu, yüzeyden gözlenemeyen çatlakların yerlerinin tespiti amacıyla sismik ultrasonik, yer radarı ve elektrik özdirenç ölçümleri alınmıştır. Yapıya deprem etkisini yaratmak amacıyla 65 tona kadar artımlı çevrimsel yük uygulanmıştır. Şekil 3a'da tasarlanan depreme dayanıklı perde yapı ve bağlı olduğu kiriş sisteminin şematik çizimi görülmektedir. Yapı elemanının boyutları ve yapının donatı özellikleri şekil üzerinde verilmiştir. Şekil 3b' de ise sol tarafta jeofizik ölçülerin alındığı betonarme yapının yük uygulanmamış durumu ve sağ tarafta da yük uygulanmıs hali görülmektedir. Sağ taraftaki yapının üzerindeki çizgiler yapıya yük uygulandıktan sonra yapının üzerinde oluşan çatlakları göstermektedir.

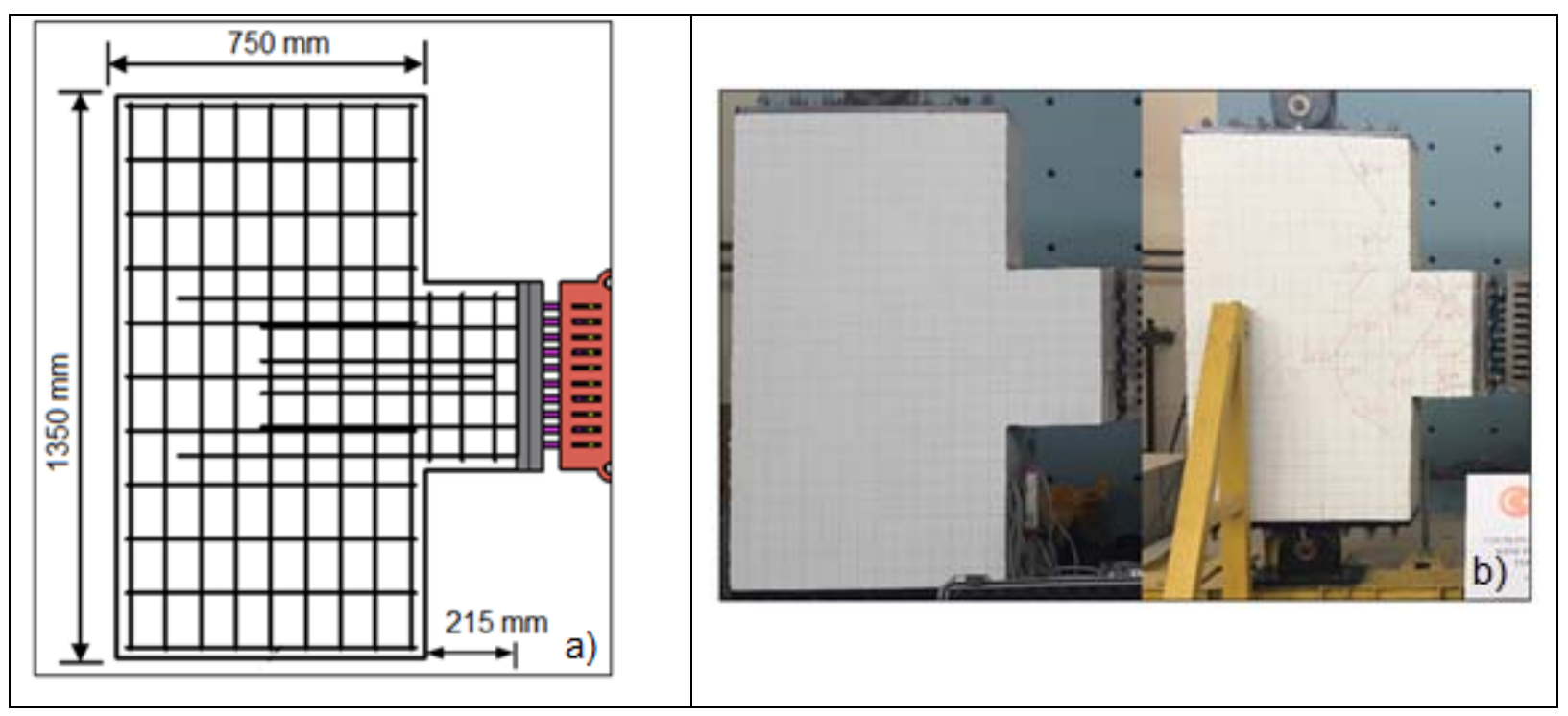

Şekil 3. a) Jeofizik ölçüler alınan betonarme yapı elemanının şematik görünümü b) Ölçüm yapılan betonarme yapının deneyden önceki ve sonraki durumu. Ölçüm hatları ve uygulanan yük sonrası oluşan deformasyonlar yapılar üzerinde çizilmiştir.

Figure 3. A schematic view of the reinforced concrete structural element on which geophysical measurements are taken b) the state of the reinforced concrete structure before and after the test. The measurement profiles and deformations after applied load are drawn on the structures. 
Kirişler üzerinde öncelikle beton dayanımı ve çatlak durumunu araştırmak amacıyla ultrasonik ölçüler alınmıştır. Betonarme yapıda ölçüler, yük uygulama öncesi ve sonrası ayrı ayrı olmak üzere toplamda 23 profilde 266 noktada alınmıştır. Yapı üzerinde ölçü hatları çizgilerle gösterilmiştir. Ölçüler $5 \mathrm{~cm}$ istasyon ve $5 \mathrm{~cm}$ profil aralıkları ile alınmıştır. Şekil 4'te kiriş boyunca toplanan ultrasonik verilerden oluşturulmuş sismik hız haritaları görülmektedir. Beton numunesine gerilme uygulanmadan önce elde edilen sismik hız haritasında (Şekil 4a) oldukça düzgün ve tekdüze (homojen) hız dağılımları gözlemlenmiştir. Beton numunesinin P-dalgası hız değerleri yaklaşık 3600-4200 m/sn aralığında olup bu değerlere göre kiriş çok iyi kalite yapı sınıfına girmektedir (Çizelge 1). Şekil 4b'de ise yapıya kuvvet uygulandıktan sonra betonun sadece hasar görmüş bölümünden alınmış ultrasonik verilerinden oluşturulmuş P-dalgası hız haritası ve Şekil $4 c$ 'de ise verilerin toplandığı kısım görülmektedir. Şekil $4 b$ incelendiğinde, betonarme yapının hasar almış bölümünde hızlarda azda olsa düşüş olduğu anlaşılmaktadır. Özellikle çatlakların sıklaştığı kısımda hasarsız yapıya göre hız dağılımı daha karmaşık bir hal almıştır. Haritada düşük hız noktalarının çatlaklar boyunca konumlandığı görülmektedir. Bu da çatlakların sadece yüzeyde değil numunenin içinde de devam ettiğini göstermektedir. Çatlakların yoğun olduğu bölgede betonarme yapının hızı 1200$2800 \mathrm{~m} / \mathrm{sn}$ arasında, numunenin hasar almamış bölümlerinde ise $3600-4000 \mathrm{~m} / \mathrm{sn}$ arasında değişmektedir.

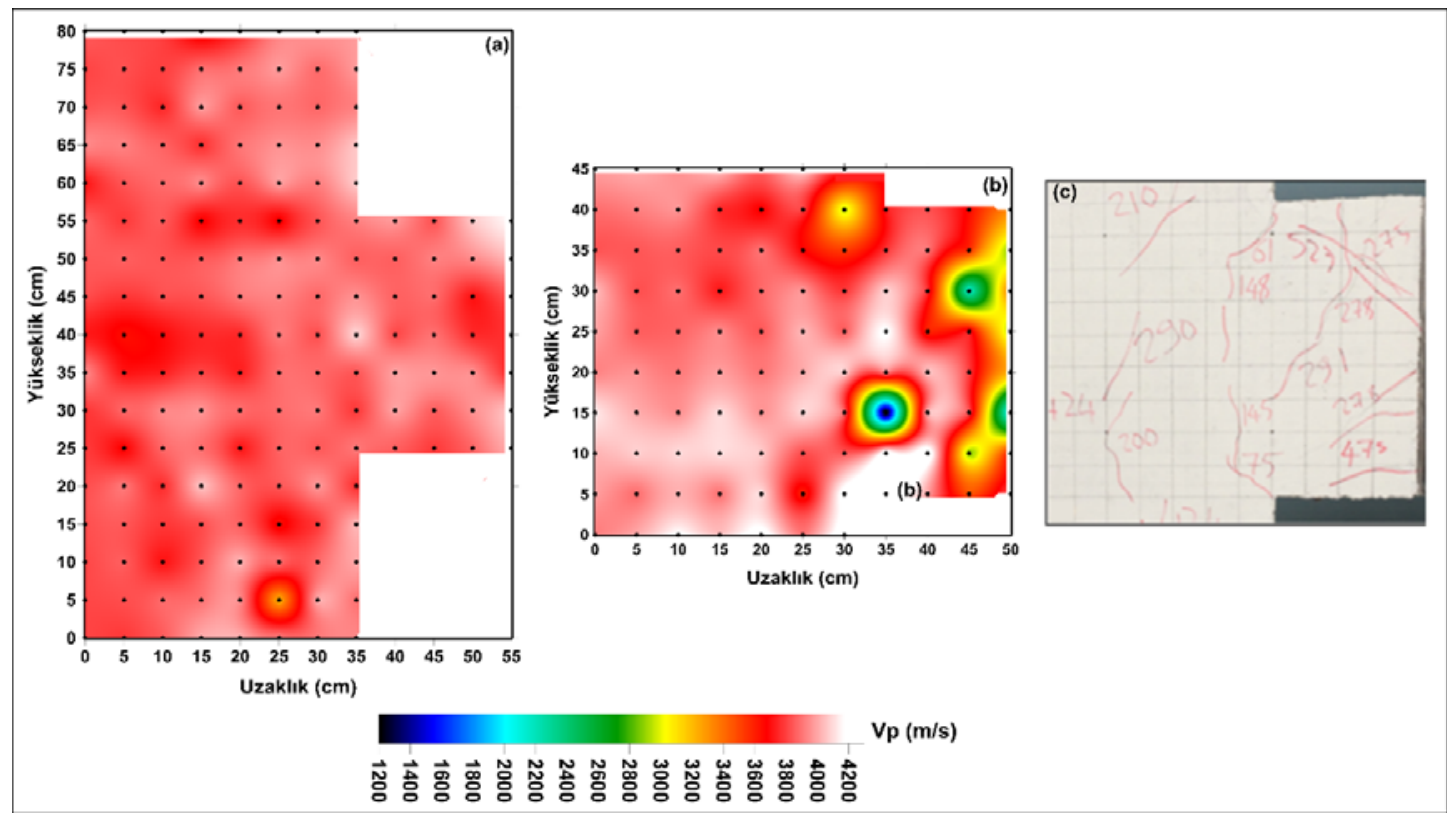

Şekil 4. Betonarme yapı üzerinde elde edilen ultrasonik boyuna dalga hız haritaları. (a) kuvvet uygulamadan önce, (b) kuvvet uygulandıktan sonra, (c) Betonarme yapıya gerilme uygulandıktan sonra deformasyonların gözlendiği kısım. Deformasyon sonrası ölçüler bu kısımda alınmıştır.

Figure 4. Ultrasonic longitudinal wave velocity maps obtained on the reinforced concrete structure (a) before applying force (b) after applying the force (c) The parts where 
deformations are observed after the stress applied to the reinforced concrete structure. Post-deformation measurements were taken in this section.

Betonarme yapı üzerinde ultrasonik ölçülerin ardından elektrik özdirenç ölçüleri alınmıştır. Özdirenç ölçü hatları yapı üzerinde çizilmiştir (Şekil 5c). Bu uygulama için ölçüler 25 profilde, $5 \mathrm{~cm}$ aralıkla Wenner elektrot dizilimi kullanılarak alınmıştır. Özdirenç ölçüleri yapı üzerinde kuvvet uygulanmadan önce ve kuvvet uygulandıktan sonra kirişlerin aynı kısımlarında ayrı ayrı alınmıştır. Kuvvet uygulanmadan önce elde edilen özdirenç haritasında yaklaşık 1,5 ile $4 \mathrm{k} \Omega . \mathrm{cm}$ arasında değişen, düşük ve tekdüze (homojen) dağılımlı özdirenç değerleri görülmüştür (Şekil 5a). Bu değerlere

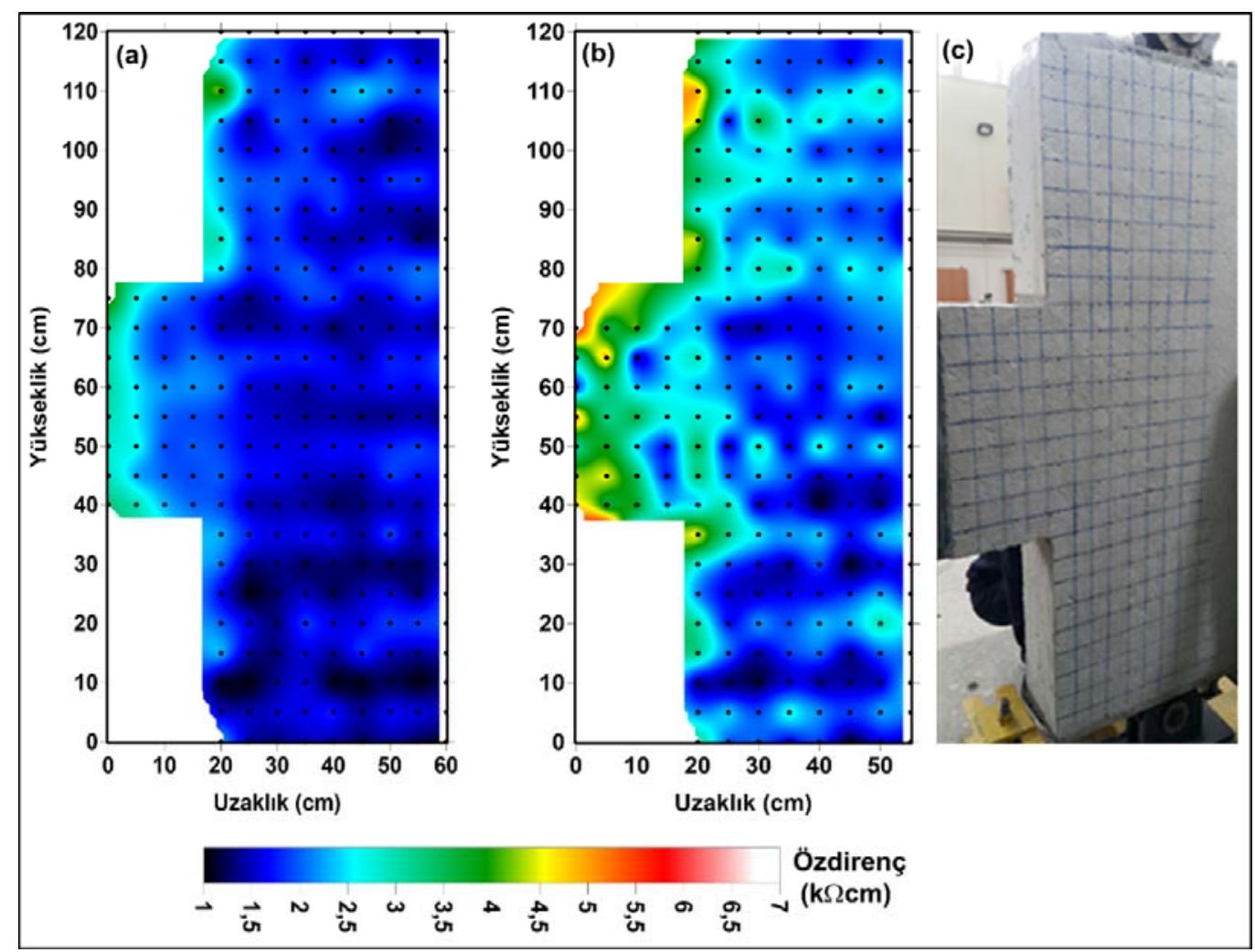

Şekil 5. Betonarme yapıda kuvvet uygulamadan önce (a) ve kuvvet uygulandıktan sonra (b) oluşturulan elektrik özdirenç haritaları. Kuvvet uygulanmadan önce betonarme yapı ve yapı üzerinde ölçüm profillerinin görünümü (c).

Figure 5. Electrical resistivity maps generated before (a) and after (b) the application of force in a reinforced concrete structure. The appearance of the measurement profiles on the reinforced concrete structure and structure before the application of force (c).

göre yapının çok yüksek korozyon durumuna sahip olduğu anlaşılmaktadır (Çizelge 2). Ancak, betonarme yapıda kullanılan donatılar yeni ve korozyona uğramamıştır. Bilinen bu 
durum nedeniyle özdirenç değerlerinin çok düşük çıkmasının, betonun yeni dökülmüş ve suya doygun olmasından ileri geldiği anlaşılmaktadır. Şekil 5b'de ise kuvvet etkisi ile hasar almış beton numunenin üzerinde alınan özdirenç ölçülerinden hazırlanan harita görülmektedir. Betonun içeriği değişmediği halde çatlamalar nedeniyle özdirençlerde kısmi bir yükselim meydana geldiği görülmüştür. Haritada özdirenç değerleri 1,2 ile 7 k $\Omega . c m$ arasında değişmektedir. Ayrıca, betonarme yapı hasar aldığı için değerlerin dağılımı hasar almamış numunenin özdirenç haritasına göre daha düzensiz bir görünüm ortaya koymuştur.

Son olarak betonarme yapı üzerinde $2.7 \mathrm{GHz}$ merkez frekanslı yer radarı cihazıyla yine kuvvet uygulama öncesi ve sonrası olmak üzere 85 profilde ölçüm alınmıştır. Elde edilen veriler işlendikten sonra, verilerden yapının görüntüsünü veren iki ve üç boyutlu kesitler oluşturulmuştur. Betonarme yapıya ait iki boyutlu yer radarı kesitlerinden biri Şekil 6' da görülmektedir. Ölçünün alındığı profilin yeri şeklin sol tarafında verilen yapı üzerinde ok ile işaretlenmiştir. Toplanan veriler yüksek frekanslı antenle toplandığı için verilere sadece temel gürültülerin kaldırılması amacıyla filtreleme işlemi uygulanmıştır. Kesitteki her bir hiperbol bir donatıya işaret etmektedir. Kesitte betonarme yapı içerisindeki çelik donatılar oldukça açık bir şekilde izlenmektedir. Kesitten birbirine yakın donatıların olduğu kısımlardaki hiperbollerin girişim yaptığı anlaşılmaktadır.

Yapıya yük uygulanmadan önce yapının başka bir kısmından alınan yer radarı ölçülerinden oluşturulan kesitlerden bir diğeri Şekil 7a' da görülmektedir. Kesitin ait olduğu profil yapı üzerinde ok ile işaretlenmiştir (Şekil 7c, d). Bu kesitin elde edilmesinde aynı veri işlem uygulamasının yanında hiperbollerin odaklanması için migrasyon işlemi de uygulanmıştır. Radar kesitinde yaklaşık $5 \mathrm{~cm}$ derinlikte görülen yan yana düzgün şekilde sıralanmış 6 adet siyah benek (şekil üzerinde oklarla işaretlenmiş), beton numunesinin içerisindeki çelik donatıları temsil etmektedir (Şekil 7a). Kesitte yapının baş ve sonundaki donatılar, cihazın boyu nedeniyle ölçülerin sıfır noktasından başlatılamayıp son noktada bitirilememesinden dolayı yarım benek olarak oluşmuştur. Yapıya yük uygulandıktan sonra yüksek frekanslı yer radarı cihazıyla alınan ölçülerden oluşturulan aynı profile ait yer radarı kesiti Şekil 7b’ de görülmektedir. Bu kesitte de önceki kesitte görülen benekler benzer olarak gözlemlenmiştir. Ancak, oluşan küçük deformasyonlar nedeniyle beneklerin yerlerinde ve şeklinde küçük değişimler meydana gelmiştir. 


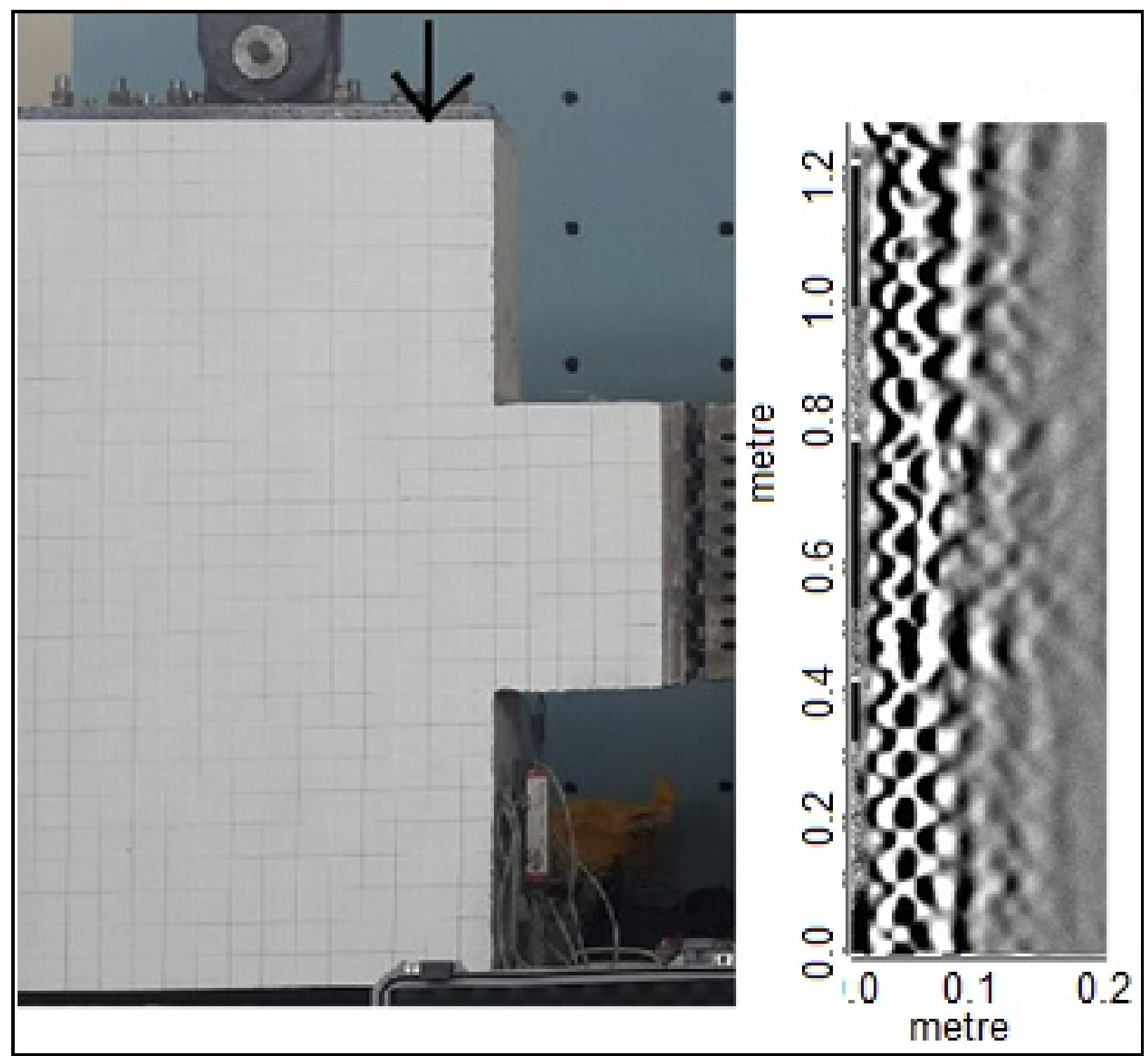

Şekil 6. Betonarme yapı elemanı ve ok ile işaretlenen profilden alınan verilerin işlenmesiyle elde edilen yer radarı kesiti.

Figure 6. The GPR section obtained by processing the data taken from the profile marked by the reinforced concrete structural element. 


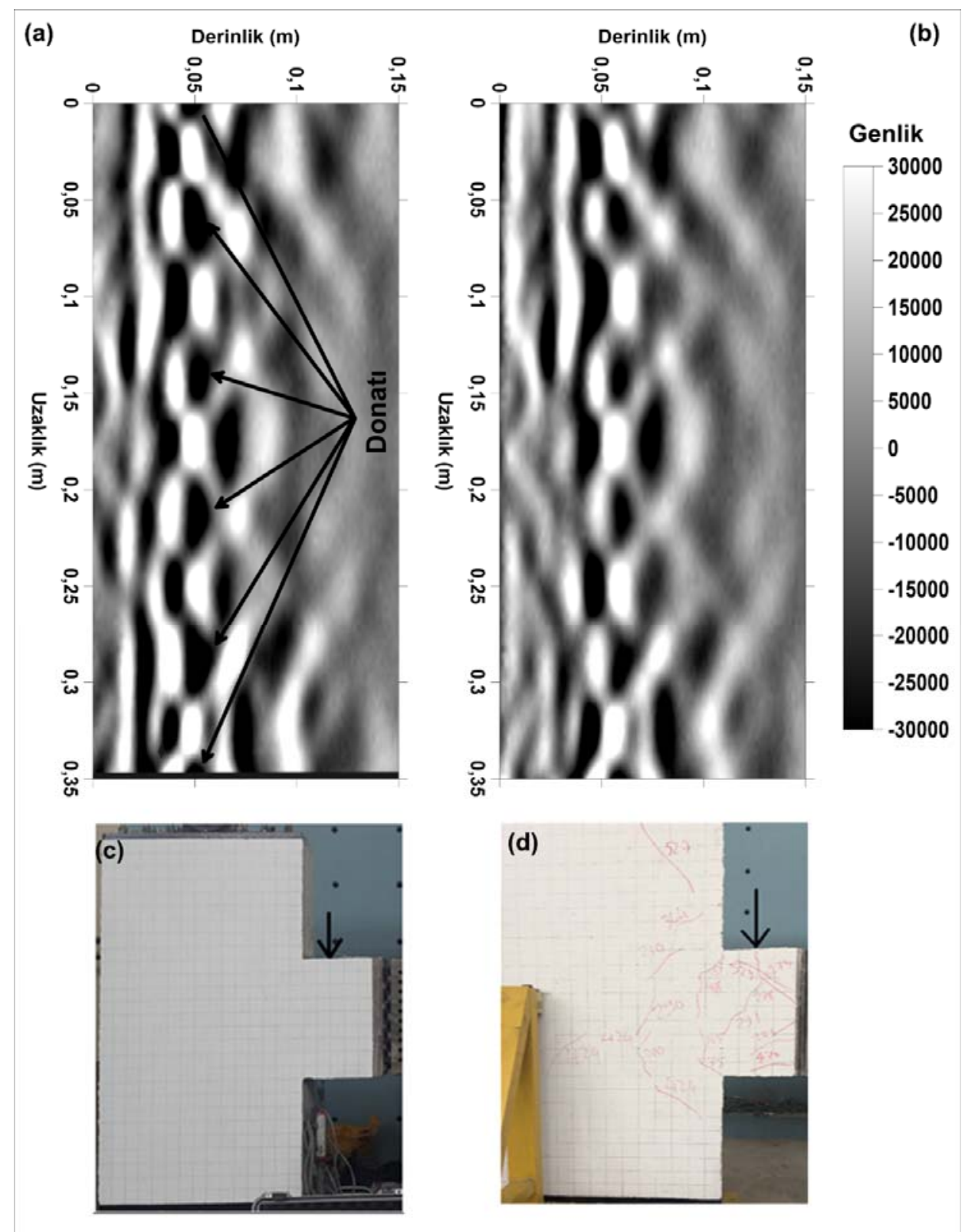

Şekil 7. Betonarme yapının gerilme öncesi (a) ve sonrası (b) için oluşturulan yer radarı kesitleri. Betonarme yapıda uygulanan gerilme öncesi (c) ve sonrası (d) için ölçüm şeması. Gerilme sonrası oluşan yüzey çatlakları şekil üzerinde gösterilmiştir (d). Yer radarı ölçüm profilinin yeri yapı üzerinde ok ile işaretlenmiştir.

Figure 7. GPR sections of the reinforced concrete structure before (a) and after (b) the stress. Measurement scheme for pre and post stress applied in reinforced concrete structure. The surface cracks formed after stretching are shown on the figure. The location of the GPR measurement profile is marked with an arrow on the structure.

Şekil 8' de ise betonarme yapı üzerinde yük uygulanması ile hasar oluşan bölümde hasar almadan önce ve sonra toplanan dikey doğrultusundaki verilerin üç boyutlu çizdirilmiş hali görülmektedir. Sol tarafta yük uygulanmadan önce, sağ tarafta ise yük uygulandıktan 
sonra alınan ölçülerin çözünürlülük sınırları içerisinde kalan bir kısmı görülmektedir. Kesitlerde ön cephede gözlenen mor renkli benekler malzeme içerisindeki çelik donatılara karşılık gelmektedir. İki adet etriye kesitin üst kısmında düz çizgi görünümündedir. Kuvvet etkisi ile hasar oluşan yapıdan alınan verilerden oluşturulan çizimdeki anomalilerde (sağ taraftaki şekil), hasar etkisi ile genliklerde zayıflama ve anomalilerin şeklinde bozulmaların meydana geldiği görülmektedir.

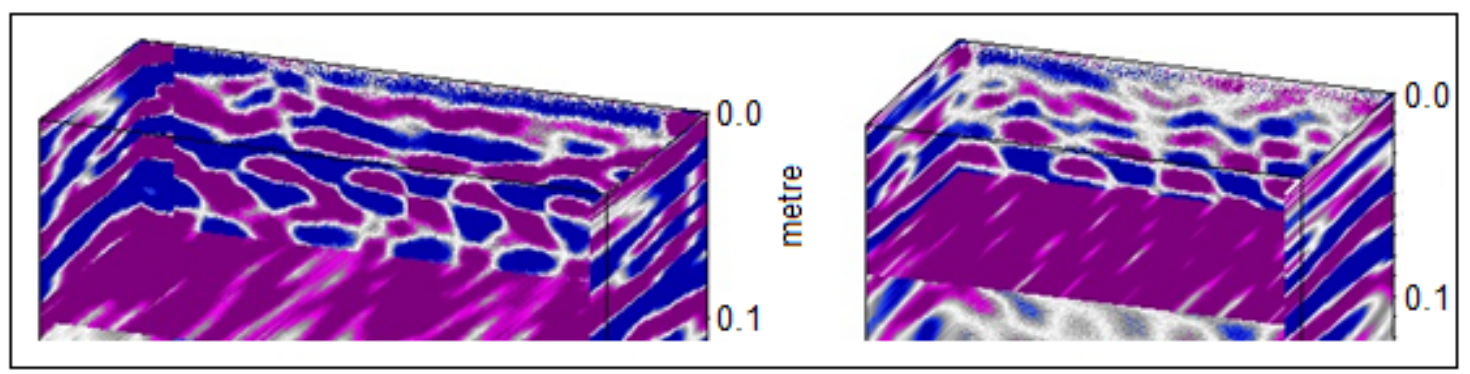

Şekil 8. Betonarme yapının kiriş kısmında deformasyon öncesi ve sonrası alınan yer radarı verilerinin üç boyutlu gösterimi.

Figure 8. Three-dimensional representation of GPR data taken before and after deformation in the beam section of the reinforced concrete structure.

Daha önce jeofizik ölçülerle hasar görmüş ve tarihi yapıların araştırıldığı pek çok çalışma gerçekleştirilmiştir. Bu çalışmada ise yeni tasarlanan bir perde betonarme yapı üzerinde jeofizik ölçüler ilk defa olarak alınmıştır. Sismik ultrasonik, GPR ve elektrik ölçüler kombine olarak uygulanarak perde betonarme yapısının tamamının içyapısı ve kalitesi başarılı bir şekilde ortaya konulmuştur. Yöntemlerin uygulaması çok hızlı ve ucuzdur. Ayrıca bu ölçülerle yapıya herhangi bir zarar verilmemiştir.

\section{SONUÇLAR}

Bu çalışmada, test amacı ile hazırlanmış bir güçlendirilmiş betonarme yapı örneği üzerinde yapılan jeofizik uygulamaların sonuçları verilmiştir. Jeofizik ölçüler yapı üzerinde yapıya bir kuvvet uygulanmadan önce ve kuvvet uygulandıktan sonra ayrı ayrı alınmıştır. $\mathrm{Bu}$ betonarme yapı üzerinde sismik ultrasonik, elektrik özdirenç ve yer radarı yöntemleri uygulanmıştır. Gerilme öncesi yapılan sismik ultrasonik ölçümlerden beton kalitesinin çok iyi olduğu anlaşılmıştır. Gerilme uygulandıktan sonra elde edilen ultrasonik hız 
haritasında çatlakların olduğu bölgelerde hızda azalış ve dalgalanma gözlenmiştir. Yapı üzerinde kuvvet uygulanmadan yapılan özdirenç ölçülerden nemlilik nedeniyle yapının düşük özdirenç değerlerine sahip olduğu, kuvvet uygulandıktan sonra ise elektrik özdirenç değerlerinde artış ve dalgalanma gözlenmiştir. Yer radarı yöntemi ile gerilme öncesi beton numunesi içerisinde bulunan donatı, etriyelerin sayısı ve yerleri net bir şekilde ortaya konulmuştur. Gerilme sonrasında betonda oluşan gözle görülemeyen çatlaklar işlenmiş yer radarı kesitlerinde gözlenmiştir. Yapı jeofiziği çalışmalarında yapıya herhangi bir zarar vermeden, hızlı bir şekilde uygulanan jeofizik yöntemlerin, yapının görünmeyen kısımları hakkında önemli bilgiler sağladığı ortaya konulmuştur.

\section{KATKI BELİRTME}

Boşluklu betonarme perde duvarlar arasındaki bağ kirişlerinde kullanılabilecek geleneksel ve yenilikçi sistemler üzerine yürütülen proje çerçevesinde hazırladıkları perde yapı elemanı üzerinde Jeofizik ölçü almamıza olanak sağladığı için Prof. Dr. Metin HÜSEM'e, makale hakkında yapıcı tavsiyelerde bulunan hakemlere ve editöre teşekkür ederiz.

\section{KAYNAKLAR}

Ahn, T., Kim, Y., Kim, S., Hwang, I., 2011. Seismic Performance of Coupling Beam Damper System. Council on Tall Building and Urban Habitat World conference October 10-12, Seoul Korea.

Akevren, S., 2010. Non-destructive examination of stone masonry historic structures quantitative IR thermography and ultrasonic testing. MSc Dissertation, The Graduate School of Natural and Applied Sciences of Middle East Technical University, Ankara, Turkey.

Andrade, C., and Alonso, C., 2004. Test methods for on-site corrosion rate measurement of steel reinforcement in concrete by means of the polarization resistance method. Materials and Structures, 37, 623-643.

Annan, A.P., 2001. Ground Penetrating Radar Workshop Notes. Mississauga, Ontario Sensors and Software Inc. 
Babacan, A.E., and Gelisli, K., 2015. Ultrasonic Investigations of Marble Columns of Historical Structures Built in Two Different Periods. Carbonates and Evaporites, 30, 357.

Barroso, E., Silva, L., Polivanov, H., 2006. Weathering and deterioration evaluation of a Brazilian cultural heritage building, IAEG .

Cecire, A.S., 2003. Nondestructive evaluation of historic structures. Dissertation, Massachusetts Institute of Technology.

Daniels. D.J.. 2004. Ground Penetrating radar 2nd edition, The Institution of Electrical Engineers, London.

Davis, J.L., and Annan, A.P., 1986. High-Resolution Sounding Using Ground Penetrating Radar. Geoscience, 13(3), 205-208.

Davis, J.L., and Annan, A.P., 1989. Ground Penetrating Radar for High-Resolution Mapping of Soil and Rock Stratigraphy. Geophysical Prospecting, 37, 531-551,

Diana, G., Fais, S., 2010. IR thermography and ultrasonic investigations in the cultural heritage field. In: 15th international conference on "cultural heritage and new technologies", Vienna.

Feldman, R.F., 1977. Non-destructive testing of concrete. CD_BD-187, National Research Council of Canada, Ottowa, Ontario, p.6.

Gosa'lbez, J., Salazar, A., Bosch, I., Miralles, R. and Vergara, L. 2006. Application of ultrasonic nondestructive testing to the diagnosis of consolidation of a restored dome. Mater Eval 64(5), 492-497.

Green, R.E., 1973. Ultrasonic Investigation of Mechanical Properties. Academic Press, New York.

Jones, R., and Gatfield, E.N., 1955. Testing concrete by an ultrasonic pulse tech. Paper No.34, London.

Krautkramer, K., 1969. Ultrasonic Testing of Materials. Springer-Verlag, New York.

Leslie, J.R., and Cheeseman, W.J., 1949. An ultrasonic method for studying deterioration and cracking in concrete structures. ACI Mater. J. 46(2), 17-36.

Mechbal, Z., Khamlichi, A., 2017. Determination of concrete rebars characteristics by enhanced post processing of GPR scan raw data. NDT E Int., 89, 30-39.

Nuzzo, L., Calia, A., Liberatore, D., Masini, N., Rizzo, E., 2010. Integration of groundpenetrating radar, ultrasonic tests and infrared thermography for the analysis of a precious medieval rose window. Adv Geosci. 24, 69-82. 
Özçelik, E., ve Gelişli, K., 2018. Betonarme Yapılarda Jeofizik Yöntemlerle Beton Kalitesi ve Yapı Donatı Durumunun Araştırıması. Uygulamalı Yerbilimleri Dergisi, 17 (1), 1-11. Popovics, J.S., 2003. NDE Techniques for concrete and masonry structures, Prog. Struct. Eng. Mater. 5, 49- 59.

Sabbağ, N., and Uyanık, O., 2018. Determination of the reinforced concrete strength by apparent resistivity depending on the curing conditions, Journal of Applied Geophysics, 155, 13-25.

Singh, T.N., and Sharma, P.K., 2008. A correlation between P-wave velocity, impact strength index, slake durability index and uniaxial compressive strength. Bulletin of Engineering Geology and the Environment, 67 (1), 17-22.

Solla, M., Asorey-Cacheda, R., Núñez-Nieto, X., Conde-Carnero, B., 2016. Evaluation of historical bridges through recreation of GPR models with the FDTD algorithm. NDT E Int. 77, 19-27.

Uyanık, O., Kaptan, K., Gülay, F.G., ve Tezcan, S., 2011. Beton Dayanımının Tahribatsız Ultrasonik Yöntemle Tayini. Yapı Dünyası, 184, 55-58.

Telford, W.M., Geldart, L.P., ve Sherif, R.E., 1990. Applied Geophysics, Cambridge University Press. 770. 